\title{
Lateralized Effects of Medial Prefrontal Cortex Lesions on Neuroendocrine and Autonomic Stress Responses in Rats
}

\author{
Ron M. Sullivan and Alain Gratton \\ Douglas Hospital Research Center, Department of Psychiatry, McGill University, Montréal, Québec Canada H4H 1R3
}

The medial prefrontal cortex (mPFC) is highly activated by stress and modulates neuroendocrine and autonomic function. Dopaminergic inputs to mPFC facilitate coping ability and demonstrate considerable hemispheric functional lateralization. The present study investigated the potentially lateralized regulation of stress responses at the level of mPFC output neurons, using ibotenic acid lesions. Neuroendocrine function was assessed by plasma corticosterone increases in response to acute or repeated 20 min restraint stress. The primary index of autonomic activation was gastric ulcer development during a separate cold restraint stress. Restraint-induced defecation was also monitored. Plasma corticosterone levels were markedly lower in response to repeated versus acute restraint stress. In acutely restrained animals, right or bilateral, but not left mPFC lesions, decreased prestress corticosterone levels, whereas in repeatedly restrained rats, the same lesions significantly re- duced the peak stress-induced corticosterone response. Stress ulcer development (after a single cold restraint stress) was greatly reduced by either right or bilateral mPFC lesions but was unaffected by left lesions. Restraint-induced defecation was elevated in animals with left mPFC lesions. Finally, a leftbiased asymmetry in adrenal gland weights was observed across animals, which was unaffected by mPFC lesions. The results suggest that mPFC output neurons demonstrate an intrinsic right brain specialization in both neuroendocrine and autonomic activation. Such findings may be particularly relevant to clinical depression which is associated with both disturbances in stress regulatory systems and hemispheric imbalances in prefrontal function.

Key words: prefrontal cortex; asymmetry; ibotenic acid; stress ulcers; corticosterone; HPA axis; clinical depression; dopamine
The medial prefrontal cortex (mPFC) is an important region in mediating responses to stressful situations. This region is known to modulate neuroendocrine function during stress by regulating the hypothalamic-pituitary-adrenal (HPA) axis (Feldman and Conforti, 1985; Meaney and Aitken, 1985; McEwen et al., 1986; Diorio et al., 1993; Herman and Cullinan, 1997) and by acting as a site for glucocorticoids to exert negative feedback modulation of HPA activity (Diorio et al., 1993). The mPFC also regulates a variety of autonomic functions associated with stress in both rats (Henke, 1984; Sullivan and Henke, 1986; Cechetto and Saper, 1990; Neafsey, 1990; Frysztak and Neafsey, 1991, 1994; Henke et al., 1992) and humans (Damasio et al., 1990; Damasio, 1994). The mPFC, in particular the infralimbic and prelimbic cortices, can directly modulate neuroendocrine and autonomic function via projections to a number of diencephalic, brainstem, and spinal control centers, and indirectly via projections to limbic areas that also regulate these regions (Terreberry and Neafsey, 1987; Hurley et al., 1991; Bacon and Smith, 1993).

The mesocortical dopamine (DA) projection originating in the ventral tegmental area provides an important modulatory input to the mPFC. This projection is potently activated in times of stress (Thierry et al., 1976; Deutch and Roth, 1990; Sullivan and Gratton, 1998) and plays a role in facilitating coping behaviors and

\footnotetext{
Received Oct. 1, 1998; revised Jan. 19, 1999; accepted Jan. 24, 1999.

This research was made possible by grants from the Medical Research Council of Canada. A.G. is a holder of an FRSQ career scientist award, and R.M.S. is a National Alliance for Research on Schizophrenia and Depression Young Investigator. We thank Darlene Francis for her assistance with the CORT assays and Dr. Michael Meaney for his helpful insights.

Correspondence should be addressed to Dr. Ron Sullivan, Douglas Hospital Research Centre, 6875 LaSalle Boulevard, Verdun, Quebec, Canada H4H 1R3. Copyright (C) 1999 Society for Neuroscience 0270-6474/99/192834-07\$05.00/0
}

protecting against stress-related pathologies (Ray et al., 1988; Scatton et al., 1988; Carlson et al., 1993; Sullivan and Szechtman, 1995), presumably by dampening the activity of mPFC output neurons. Recent studies however, have revealed numerous left/ right hemispheric asymmetries in the mesocortical DA projection in both basal conditions (Slopsema et al., 1982; Carlson et al., 1993; Sullivan and Szechtman, 1994; Sullivan et al., 1998) and in response to stress (Carlson et al., 1991, 1993, 1996; Sullivan and Szechtman, 1995; Sullivan and Gratton, 1998).

The purpose of the present study was therefore twofold. First, we sought to describe more precisely the role of the $\mathrm{mPFC}$ in regulating neuroendocrine and autonomic changes associated with either acute or repeated stress by using ibotenic acid to destroy the intrinsic (including output) neurons of the mPFC. Second, we wanted to determine whether such manipulations of the left and right mPFC reveal inherent functional asymmetries in the regulation of physiological stress responses, as their DAergic inputs have been shown to do.

As an index of neuroendocrine activation, we examined the elevation in plasma corticosterone (CORT) levels after either the acute or repeated exposure to a brief room temperature restraint stress. The primary index of autonomic responsivity was the formation of gastric ulcer pathology in response to a longer duration cold restraint, a process known to be mediated by the vagus (Ray et al., 1987; Glavin et al., 1991).

\section{MATERIALS AND METHODS}

Animals. Fifty-nine male Sprague Dawley rats (Charles River, St. Constance, Quebec) weighing 300-350 gm were used in the present study. The animals were housed singly with food and water available ad libitum and were maintained on a $12 \mathrm{hr}$ light/dark schedule (lights on at 8:00 
Table 1. Stress protocols of acute and repeated restraint treatments

\begin{tabular}{|c|c|c|c|c|}
\hline \multirow[b]{2}{*}{ Treatment } & \multirow[b]{2}{*}{ Lesions } & \multirow[b]{2}{*}{$N$} & \multicolumn{2}{|l|}{ Stress protocol } \\
\hline & & & $\begin{array}{l}\text { No. } 20 \text { min restraint sessions } \\
\text { (room temperature) }\end{array}$ & No. $2.5 \mathrm{hr}$ cold restraints \\
\hline \multirow[t]{4}{*}{ Acute } & Sham & 10 & 1 (day 15$)$ & 1 (day 15) \\
\hline & Left & 7 & " & " \\
\hline & Right & 7 & $"$ & $"$ \\
\hline & Bilateral & 7 & " & $"$ \\
\hline \multirow[t]{4}{*}{ Repeated } & Sham & 7 & 5 (days 11-15) & $"$ \\
\hline & Left & 7 & " & $"$ \\
\hline & Right & 7 & $"$ & $"$ \\
\hline & Bilateral & 7 & $"$ & $"$ \\
\hline
\end{tabular}

It can be seen that although the acute groups received a single 20 min restraint, repeated groups received the same stress on five occasions. All animals were exposed to a single cold restraint stress at the completion of testing on the 15 th postsurgical day.

A.M.). All procedures in the present study conformed to the guidelines of the Canadian Council on Animal Care.

Surgery and testing procedures. On the day of surgery, rats were pretreated with atropine sulfate $(0.1 \mathrm{mg} / \mathrm{kg}$, i.p. $)$ and anesthetized with sodium pentobarbital $(60 \mathrm{mg} / \mathrm{kg}$, i.p.). Animals received either sham $(n=17)$ or ibotenic acid lesions in the left, right, or bilateral mPFC $(n=$ 14 per group). Two adjacent injection sites were targeted in each hemisphere [anteroposterior (AP) +3.5 , lateral $(\mathrm{L}) \pm 0.8$ bregma, ventral (V) -4.7 from dura, and $\mathrm{AP}+2.5, \mathrm{~L} \pm 0.8, \mathrm{~V}-3.5$ with skull horizontal as described in Paxinos and Watson, 1982]. Solutions $(5 \mu \mathrm{g} / 0.5 \mu \mathrm{l}$ of ibotenate or saline vehicle) were injected via a $1 \mu$ l Hamilton microsyringe that was lowered stereotaxically into the brain. Each injection was performed over a 2 min period, with an additional 4 min allowed for diff usion away from the tip of the microsyringe.

Fifteen days after surgery, all rats were placed in Plexiglas large rodent restrainers for $20 \mathrm{~min}$ at room temperature, with blood samples $(\sim 50 \mu \mathrm{l})$ collected at 0,20 , and $80 \mathrm{~min}$ from the tip of the tail vein, to determine plasma CORT levels under prestress, peak, and recovery conditions, respectively. Rats were returned to their home cages between the 20 and $80 \mathrm{~min}$ sampling periods. Samples were always collected between 10:00 A.M. and 2:00 P.M. Immediately after the 80 min sampling, rats underwent a $2.5 \mathrm{hr}$ cold restraint stress $\left(4^{\circ} \mathrm{C}\right)$ in the same restrainers, so that stress ulcer formation could be assessed. This was the minimum duration of cold restraint required to reliably observe the development of gastric pathology in control animals.

As summarized in Table 1, rats in each lesion condition were randomly subdivided into acute and repeated restraint treatments, based on the 20 min room temperature restraint for plasma CORT assessment. The neuroendocrine data for the repeated groups thus represents the fifth exposure to the same (mild) stressor. All rats in the study received a single, subsequent cold restraint stress on day 15.

As well, during the first four daily $(20 \mathrm{~min})$ restraint sessions in the repeated groups, the number of fecal boli were recorded during the restraint sessions as a general index of autonomic reactivity. This measure was not recorded on the final test day when blood sampling was also conducted.

The inclusion of repeated (as well as acute) restraint groups allowed for the assessment of habituation of the plasma CORT stress response and for the possible dissociation of the mPFC regulation of an acute stress response versus one that incorporates a learning/experiential component. This design also provided the opportunity to study whether repeated experience with a mild stressor would be adaptive or maladaptive to the ability to cope with a subsequent more stressful situation (cold restraint).

CORT assay. Plasma CORT levels were measured by radioimmunoassay as previously described by Krey et al. (1975) with a highly specific CORT antiserum (B3-163; Endocrine Sciences, Tarzana, CA) and ${ }^{3} \mathrm{H}-$ CORT $(101.0 \mu \mathrm{Ci} / \mathrm{mmol}$; New England Nuclear, Boston, MA) as tracer. The minimum level of detection with the assay is $1 \mathrm{ng} / \mathrm{ml}$. The antiserum cross-reacts slightly with desoxycorticosterone $(\sim 4 \%)$ but not with cortisol $(<1 \%)$.

Stress ulcer assessment and histology. Immediately after cold restraint, animals were deeply anesthetized with chloral hydrate $(400 \mathrm{mg} / \mathrm{kg}$, i.p.). Stomachs were dissected out, cut along the greater curvature, and washed in cold water. They were then examined by an experimenter who was blind to the treatment conditions, with a dissecting microscope equipped with an ocular reticle and measured to the nearest $0.1 \mathrm{~mm}$ for the total length of mucosal hemorrhages (ulceration) in the glandular portion of the stomach. Adrenal glands were also dissected out at this time and weighed to the nearest $0.1 \mathrm{mg}$. Rats were perfused intracardially with $0.9 \%$ saline and $10 \%$ formalin and brains removed for histological purposes. Brains were later sectioned at $25 \mu \mathrm{m}$ at $-20^{\circ} \mathrm{C}$ and stained with thionin to determine the extent of ibotenate-induced cell loss in the mPFC.

Statistical analysis. For the analysis of plasma corticosterone levels, acute and repeated restraint treatments were analyzed separately, because these treatment differences were expected to substantially affect this measure. For each treatment a two-factor ANOVA was performed with factors of lesion (sham, left, right, bilateral) and sample $(0,20$, and $80 \mathrm{~min}$ ), with repeated measures on sample. The single dependent measure of gastric stress pathology was examined with a two-factor (lesion $\times$ treatment) ANOVA. The index of defecation across days of restraint was analyzed with a two-factor (lesion $\times$ days) ANOVA with repeated measures on days. Finally, adrenal weights were analyzed with a three-factor (lesion $\times$ treatment $\times$ side) ANOVA with repeated measures on the within subjects factor of side (left or right adrenal). After significant main effects or interactions, individual group comparisons were performed using Tukey's post hoc analysis. In addition, correlational comparisons were made between variables using Pearson's test of correlation coefficients. All statistical tests were performed with SPSS/ $\mathrm{PC}+$ software.

\section{RESULTS \\ Histology}

Figure 1, $A$ and $B$, demonstrates the extent of ibotenate-induced cell loss in mPFC-lesioned animals. The minimum amount of damage in all lesioned animals included the infralimbic and prelimbic cortex as well as the rostral (pregenual) portion of the anterior cingulate. Additional damage in a number of animals extended rostrally to the ventromedial orbitofrontal cortex and posteriorly to more caudal regions of (supragenual) cingulate, and in some cases dorsally to the cortical surface in the region of the injection cannula tracts. In bilateral lesion groups, the extent of cortical lesions was highly symmetrical in individual animals, and lesions in left and right unilateral groups were indistinguishable in their extent. Unilateral lesions never infringed on the contralateral cortex and in no cases were subcortical structures affected. Finally, in no single group did variations in the total extent of lesion appear to be related to any of the stress measures obtained in the study, suggesting that the most relevant cortical region or regions mediating the described effects on stress responses are those within the area of minimal lesion-induced damage common to all lesioned animals. 


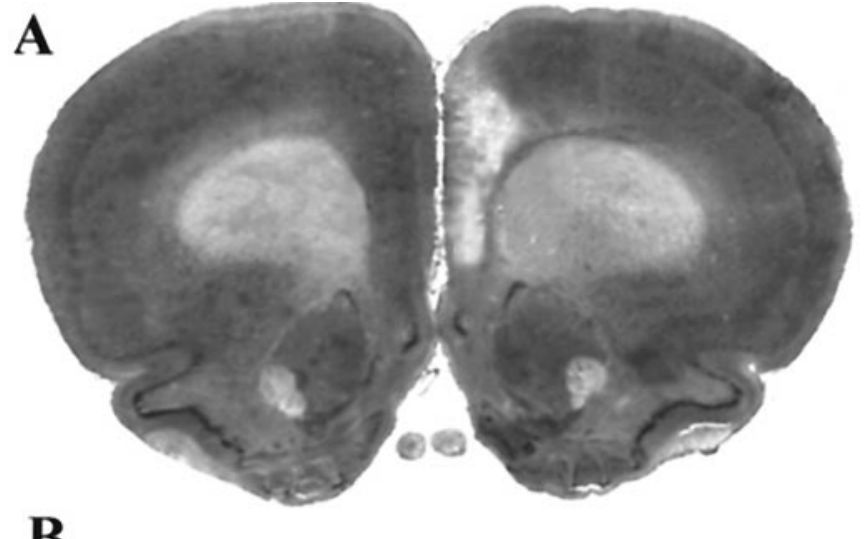

B
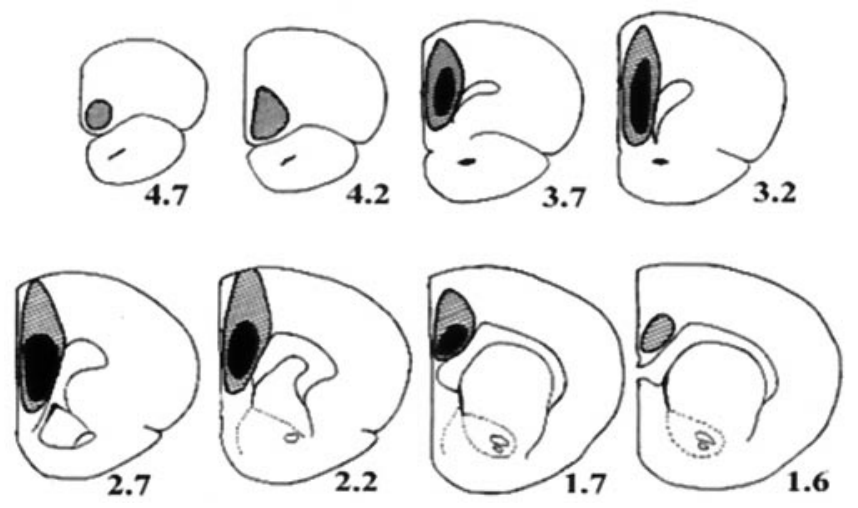

Figure 1. Extent of ibotenate-induced cell loss in mPFC-lesioned rats. $A$ depicts the typical degree of cell loss in infralimbic, prelimbic, and cingulate cortex, in this case in a right-lesioned animal. In $B$, black and shaded regions respectively represent the minimum and maximum extent of cell loss across animals. Numbers represent distance (in millimeters) anterior to bregma. See Results for additional detail.

\section{Effects of lesions and treatments on plasma corticosterone profiles}

Figure 2 depicts the plasma CORT levels across lesion and treatment conditions. Animals adapted markedly to the repeated restraint condition; (initial analysis revealed a treatment effect of $\left.F_{(1,51)}=83.46 ; p<0.00005\right)$. The results of statistical analysis for acute and repeated treatments are detailed in the Figure 2 legend. Lesions of the mPFC reduced plasma CORT levels, such that with acute treatment, prestress levels were reduced by right or bilateral lesions, whereas in repeatedly restrained animals, stressinduced increases in CORT were suppressed by right or bilateral lesions. Left lesions did not significantly alter plasma CORT at any time. The large sample effects in each treatment condition reflect the typically large CORT increases as a function of restraint.

\section{Lesion effects on cold restraint-induced gastric pathology}

As demonstrated in Figure 3, mPFC lesions resulted in dramatic and highly asymmetrical reductions in stress ulcer formation resulting from the single exposure to cold restraint stress, regardless of previous experience with acute or repeated mild stress (20 min restraint at room temperature). Bilateral lesions greatly decreased gastric stress pathology. Right lesions alone were able to fully reproduce the effect of bilateral lesions, whereas left mPFC lesions had no significant effect on this autonomically mediated response to stress.

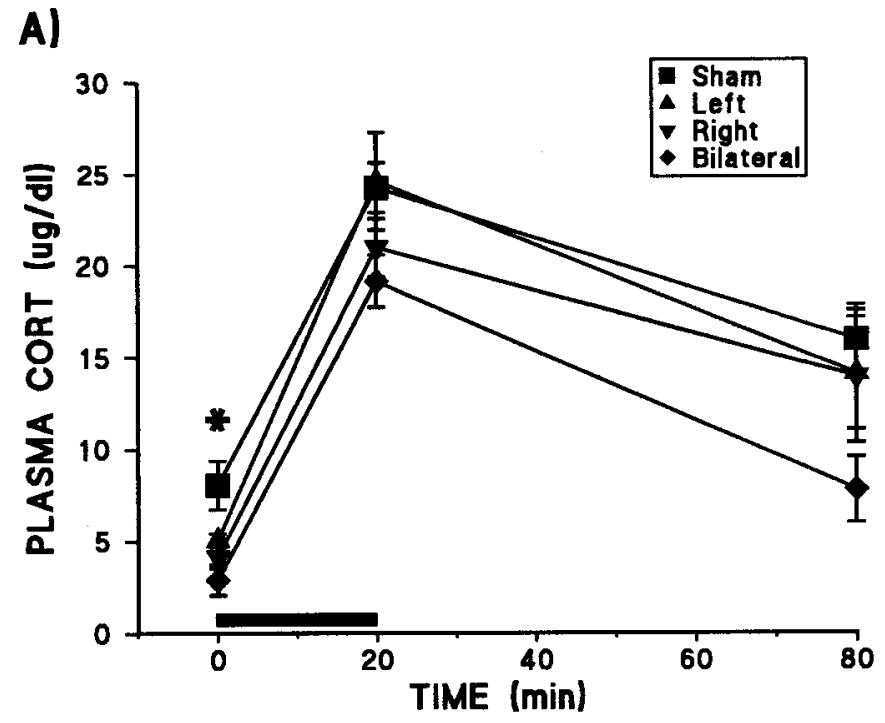

B)

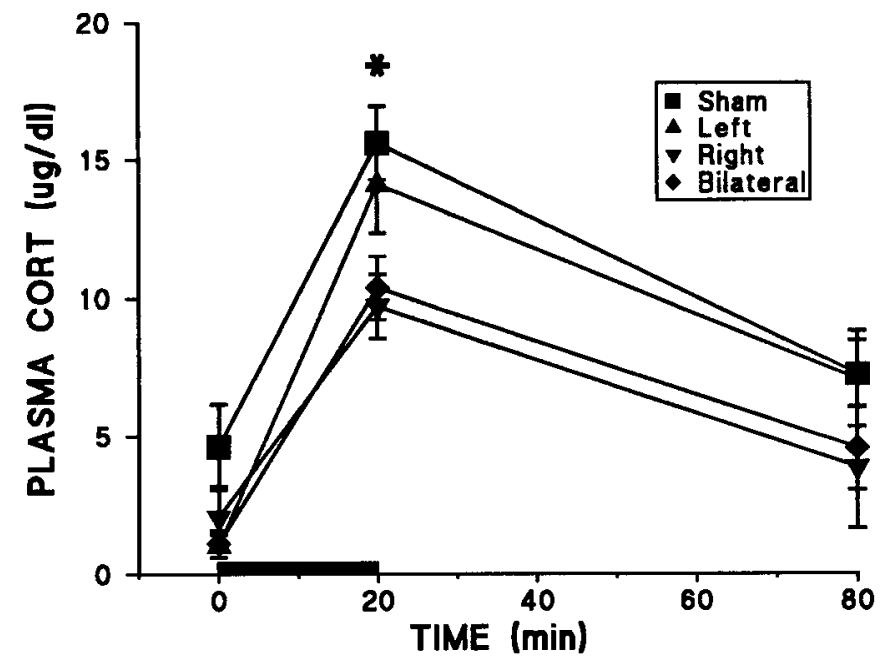

Figure 2. Effects of mPFC ibotenate lesions and treatments on mean $( \pm$ SEM) plasma CORT levels in acutely $(A)$ and repeatedly $(B)$ restrained rats. The treatment difference in magnitude of CORT levels is reflected by the different scales of the two figures, because the CORT levels of repeated restraint groups were approximately half those of acute restraint animals at all time points, indicating a marked HPA adaptation to this stressor. Solid bars depict the $20 \mathrm{~min}$ period of restraint stress (room temperature). In acutely restrained animals, significant main effects were found for both lesion $\left(F_{(3,27)}=5.18 ; p=0.006\right)$ and sample $\left(F_{(2,54)}=\right.$ $87.45 ; p<0.0005)$, with no lesion $\times$ sample interaction. Although $\mathrm{mPFC}$ lesions tended to suppress CORT levels across samples, group differences were only significant at the prestress time point, because both right and bilateral groups were reduced relative to shams (Tukey's post hoc analysis; $\left.{ }^{*} p<0.05\right)$. As with acute restraint, repeated restraint treatment revealed significant effects for lesion $\left(F_{(3,24)}=5.66 ; p=0.004\right)$ and sample $\left(F_{(2,48)}=58.45 ; p<0.0005\right)$ with no interaction. In this case, significant group differences were seen only in peak CORT levels, because both right and bilateral groups were significantly suppressed relative to shams (Tukey's post hoc analysis; *p $<0.05$ ).

\section{Effects of cortical lesions on restraint-induced defecation}

During once daily $20 \mathrm{~min}$ room temperature restraint sessions, left-lesioned animals were more frequently observed to struggle excessively and to vocalize occasionally, unlike the other rats. The number of fecal boli was used as an index of emotional and 


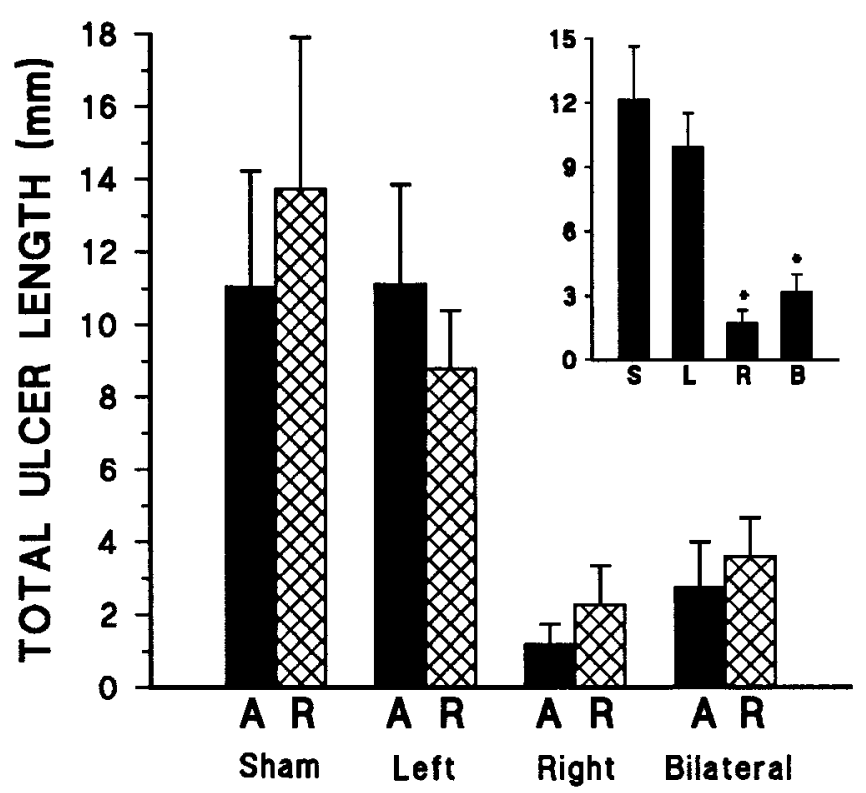

Figure 3. Mean total ulcer length $( \pm \mathrm{SEM})$ in mPFC-lesioned rats induced by a single $2.5 \mathrm{hr}$ cold restraint session. A significant effect of mPFC lesion was observed $\left(F_{(3,58)}=8.98 ; p<0.0005\right)$, with no significant effect of treatment and no lesion $\times$ treatment interaction. Regardless of previous experience with acute $(A)$ or repeated $(R) 20$ min restraint stress, bilateral and right lesion groups each differed significantly from both the shams and left-lesioned animals (Tukey's post hoc analysis; * $p<$ 0.05 in each case). Left-lesioned rats did not differ from shams, nor did right-lesioned rats differ from the bilateral lesion group. The inset reveals these pronounced lesion effect with treatments collapsed. $S, L, R$, and $B$ refer to sham, left, right, and bilateral $\mathrm{mPFC}$ lesion groups, respectively.

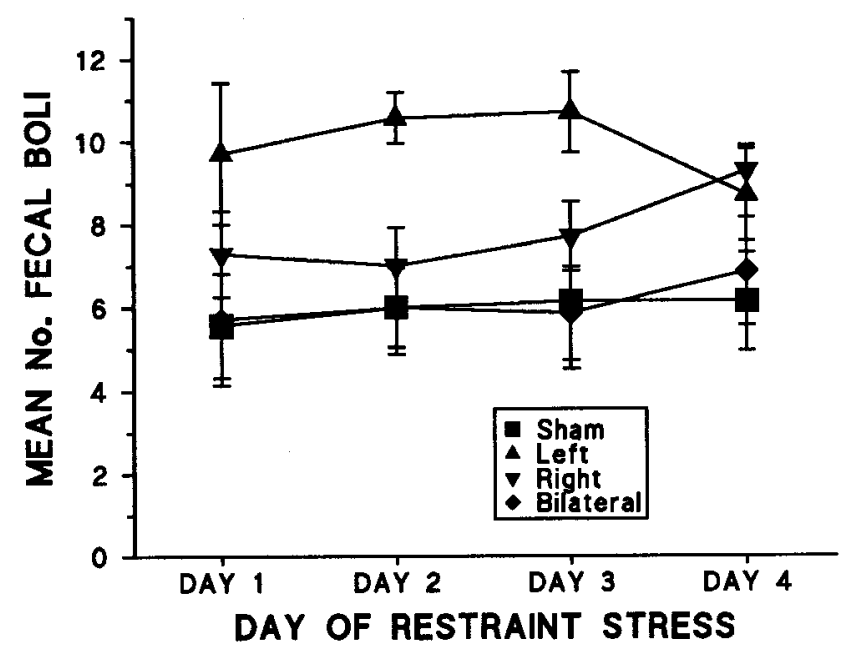

Figure 4. Mean defecation in response to daily 20 min restraint sessions. A significant lesion effect was found on this measure $\left(F_{(3,24)}=6.82 ; p=\right.$ 0.002 ), with no effect for days and no interaction for lesion $\times$ days. Rats with left mPFC lesions defecated to a greater extent than all other groups across days of testing.

autonomic reactivity, and as revealed in Figure 4, left-lesioned rats defecated more across days than other groups. Rats did not demonstrate habituation on this measure across days of testing.

\section{Left/right asymmetry in mean adrenal weights}

As depicted in Figure 5, left adrenal weights were significantly greater than right adrenal weights across animals. The mean $( \pm$ SEM) weights for left and right adrenals across groups were 29.6

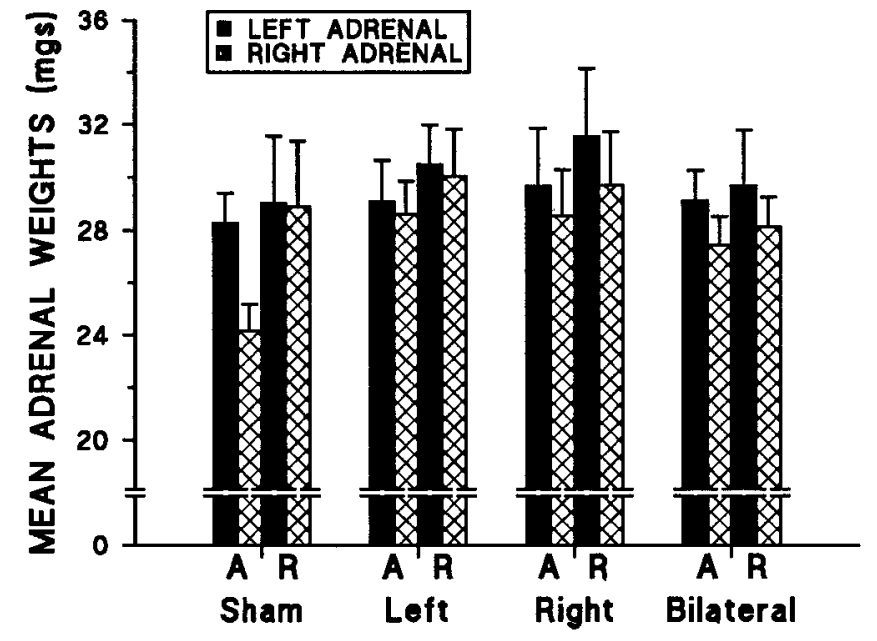

Figure 5. Left/right asymmetry in mean adrenal weights. A significant main effect was observed for side $\left(F_{(1,51)}=7.56 ; p=0.008\right)$, because the left adrenal was larger across animals. There were no significant effects for either lesion or treatment on this gross measure of neuroendocrine status, and no significant interactions were found. The $A$ and $R$ represent acute and repeated restraint treatment conditions, respectively.

(4.8) and 27.9 (4.5) $\mathrm{mg}$, respectively. This measure was unaffected by $\mathrm{mPFC}$ lesion or by restraint treatment conditions.

\section{Correlations between stress pathology and neuroendocrine measures}

In general, stress ulcer pathology was positively correlated with plasma CORT levels, particularly in repeatedly stressed animals. In these animals, the most notable correlation was between ulcer pathology and peak CORT levels $(r=0.56 ; p=0.002 ; n=28)$. The same relationship in acute animals failed to reach significance $(r=0.21$, NS).

An additional measure of potential interest was individual adrenal gland asymmetry, computed as $(\mathrm{L}-\mathrm{R}) /(\mathrm{L}+\mathrm{R})$, which was found to be related to stress measures in intact shams, but not in animals with mPFC manipulations. In acute shams, adrenal asymmetry was significantly related to ulcer pathology $(r=$ $-0.72 ; p=0.020 ; n=10)$. In the repeated treatment shams this relationship was lost, however in this group, adrenal asymmetry was related to plasma corticosterone recovery levels $(r=-0.82$; $p=0.024 ; n=7)$.

\section{DISCUSSION}

A principal finding of the present study was that mPFC lesions suppressed HPA activity in response to acute or repeated restraint stress. Either right or bilateral lesions reduced prestress plasma CORT levels in acutely restrained animals, whereas the same lesions in repeatedly restrained animals decreased the peak stress-induced CORT response. Left mPFC lesions did not significantly affect plasma CORT levels. In response to cold restraint stress, mPFC lesions caused a substantial and lateralized reduction in stress ulcer pathology, as right brain lesions were both necessary and sufficient to inhibit ulcer formation, whereas left lesions were without effect. Restraint-induced defecation was increased by left mPFC lesions alone, and adrenal gland weights exhibited a left-biased asymmetry, regardless of lesion or treatment conditions.

Before discussing the lateralized nature of mPFC lesion effects, it is necessary to comment generally on their direction. The inhibitory effects of ibotenate lesions on HPA function suggest 
that mPFC output neurons normally stimulate the HPA axis. This is supported by the finding that electrical stimulation of this region increases plasma CORT levels (Feldman and Conforti, 1985). One study however, using bilateral thermal lesions of mPFC (including anterior cingulate), reported no change in basal or peak plasma CORT levels in response to 20 min restraint stress but an elevation in poststress recovery levels (Diorio et al., 1993). This apparent discrepancy may reflect lesion differences (additional fiber damage with thermal lesions), placement differences (the present lesions appear to involve a greater area of mPFC), and possibly additional procedural differences.

The lesion-induced suppression of stress ulcer formation is consistent with reports that electrolytic lesions or neuronal inhibition of mPFC and/or anterior cingulate decrease stress-induced gastric pathology (Sullivan and Henke, 1986; Henke et al., 1992). Conversely, electrical stimulation or neuronal disinhibition of these regions increase gastric pathology (Henke, 1984; Sullivan and Szechtman, 1995).

The present decrease in plasma CORT levels as a function of repeated restraint parallels the habituation of HPA activation previously described after repeated experience with the same stressor (Hauger et al., 1990; Lachuer et al., 1994; Bhatnagar and Meaney, 1995). Although less commonly noted, the present repeated restraint groups also showed lower prestress CORT levels, perhaps indicating a generalized adaptation to this particular procedure. Despite the HPA adaptation to mild restraint, this experience was neither adaptive nor maladaptive for subsequent stress ulcer formation after cold restraint stress. Although HPA activation frequently habituates with repeated same stress experience, stress responses are often exaggerated after later exposure to a heterotypic stressor (Scribner et al., 1991; Aguilera, 1994; Bhatnagar and Meaney, 1995). This pattern however, is not universal (Spencer and McEwen, 1990; Aguilera, 1994) and depends on the stimulus properties (e.g., intensity) of the stressors. The present results demonstrate that differential experience with mild stress did not significantly affect the response to this heterotypic stressor and measure of pathology.

An interesting association between these two stress measures emerged however, as plasma CORT levels and ulcer formation showed significant positive correlations in repeatedly but not acutely restrained animals. This suggests that whereas peak CORT responses to acute stress may not predict susceptibility to stress pathology, failure to adapt to repeated mild stress may signify vulnerability to the pathological effects of more formidable stressors. Although corticosteroids are known to be ulcerogenic (Borsch and Schmidt, 1985), the above relationship does not imply causality, and interactions between HPA mechanisms and autonomically mediated stress ulcer formation are highly complex (Glavin et al., 1991).

The pattern of lesion-induced suppression of HPA function differed between acute and repeated restraint treatments. Stressinduced CORT elevations were reduced only in repeatedly restrained groups, suggesting a role for the mPFC in integrating experience with the modulation of neuroendocrine function. Medial cortical modulation of stress ulcer development has also been shown to vary as a function of experience, using a longer repeated stress protocol (Sullivan and Henke, 1986).

The present findings on HPA regulation suggest that an intact right $\mathrm{mPFC}$ is necessary for maximal stress-induced activation, particularly for previously experienced stressors. HPA function in rats has been related to turning behavior (LaHoste et al., 1988), but not directly to cortical asymmetries. Human data however, suggest a normal right hemisphere dominance in the control of cortisol secretion (Henry, 1997; Wittling, 1997). Furthermore, human studies have described the experience-dependent maturation of neural systems in corresponding frontal cortical regions, which generate stress-regulating coping strategies and are lateralized predominantly to the right hemisphere (Schore 1996, 1997).

Indeed, the most notable aspect of the present findings concerns the extent of lateralized regulation of stress responses at the level of the $\mathrm{mPFC}$ in the rat. Although cerebral laterality in animals remains an underappreciated phenomenon, there are many such examples involving stress or emotionality-related processes, most commonly suggesting preferential roles for right brain mechanisms (Denenberg, 1981; Carlson et al., 1991, 1993, 1996; Davidson et al., 1992; Adamec and Morgan, 1994; Coleman-Mesches and McGaugh, 1995; Sullivan and Szechtman, 1995; Sullivan and Gratton, 1998).

The presently reported cerebral asymmetry in the suppression of stress ulcer formation is consistent with findings of a similar study in rats using 6-hydroxydopamine lesions of the mPFC (Sullivan and Szechtman, 1995). The latter demonstrated that right but not left lesions significantly increased cold restraint stress ulcers, most likely by disinhibiting the same mPFC neurons lesioned in the present study. These studies suggest that although the right mPFC may be necessary to mount a normal stress response, excessive activity of this region may be maladaptive. Prelimbic and infralimbic regions of $\mathrm{mPFC}$ are considered visceral motor regions and exert considerable influence over autonomic function (Cechetto and Saper, 1990; Neafsey, 1990). Unfortunately, studies of lateralized autonomic regulation in rats are lacking. Human studies have described right brain dominance in autonomic activation in particular and emotional expression in general (Gainotti, 1983, 1987; Davidson, 1992; Wittling, 1997; Meadows and Kaplan, 1994), and such processes have been attributed importantly to the medial (orbital) prefrontal cortex (Damasio et al., 1990; Damasio, 1994; Schore, 1996, 1997).

The present measure of restraint-induced defecation was also asymmetrically affected by mPFC lesions, with left lesions increasing this response. Considering defecation a physiological index of emotional reactivity, this result profile conforms with earlier studies examining the effects of large unilateral cortical lesions on various emotionality measures in rats (Denenberg, 1981; Denenberg and Yutzey, 1985). Although the right cortex was found to mediate such behaviors, the left cortex inhibited the emotional expression of the right, as left lesions alone resulted in greater than control levels on such measures. This pattern of results was not evident on the present index of neuroendocrine function, although in both treatment conditions, there was a nonsignificant trend for left lesions to produce the greatest stressinduced CORT elevations as percent prestress levels (data not shown). The fact that left lesions did not produce greater than control levels of gastric pathology may reflect the greater duration and intensity of cold restraint stress. Data suggest that the left $\mathrm{mPFC}$ is specialized in generating coping strategies for mild or initial stress exposure, whereas right $\mathrm{mPFC}$ mechanisms predominate in situations of prolonged or uncontrollable stress (for detailed descriptions, see Carlson et al., 1991, 1993; Sullivan and Szechtman, 1995; Sullivan and Gratton, 1998). In the latter cases, interhemispheric influences of the nature described above may be rendered ineffective.

Finally, we report a left-biased asymmetry in adrenal gland weights, corroborating previous reports in both humans and rats 
(Freitas et al., 1978; Rubin and Phillips, 1991; Gerendai and Halasz, 1997). The present lesions and stress protocols did not differentially affect this gross measure. Variations in asymmetrical adrenal regulation have been related to various human pathologies, particularly depression (Otto et al., 1991; Wittling and Schweiger, 1993; Szigethy et al., 1994). The left-biased adrenal asymmetry may have an adaptive function, because in the present control animals, reversals of the normal adrenal asymmetry were correlated with increased ulcer pathology and elevated poststress CORT levels, possibly suggesting heightened vulnerability to stress. These relationships were less evident in animals with mPFC manipulations.

Overall, the data suggest a preferential role for the right mPFC in activating physiological stress responses. Such specialization may reflect perceptual processes and/or the integration of stressrelated inputs with appropriate outputs for neuroendocrine and autonomic regulation. These data may have clinical relevance to major depressive disorders, where heightened stress sensitivity and impaired coping ability coexist with disturbances in both cerebral laterality and stress-regulating systems (Barden et al., 1995). Studies have revealed that either left frontal hypofunction or right frontal hyperfunction is associated with depressed states (Schaffer et al., 1983; Henriques and Davidson, 1991; George et al., 1996). Specifically, the left ventromedial prefrontal region exhibits both volumetric and metabolic reductions in unipolar and bipolar depressed patients (Drevets et al., 1997). Taken together with animal findings, these studies emphasize the pathological potential of imbalances within the mPFC, the functional distinctness of the left and right $\mathrm{mPFC}$, and the need to study normal and abnormal asymmetries at this level.

\section{REFERENCES}

Adamec RE, Morgan HD (1994) The effect of kindling of different nuclei in the left and right amygdala on anxiety in the rat. Neuroscience $55: 1-12$.

Aguilera G (1994) Regulation of pituitary ACTH secretion during chronic stress. Front Neuroendocrinol 15:321-350.

Bacon SJ, Smith AD (1993) A monosynaptic pathway from an identified vasomotor centre in the medial prefrontal cortex to an autonomic area in the thoracic spinal cord. Neuroscience 54:719-728.

Barden N, Reul JM, Holsboer F (1995) Do antidepressants stabilize mood through actions on the hypothalamic-pituitary-adrenocortical system? Trends Neurosci 18:6-11.

Bhatnagar S, Meaney MJ (1995) Hypothalamic-pituitary-adrenal function in chronic intermittently cold-stressed neonatally handled and nonhandled rats. J Neuroendocrinol 7:97-108.

Borsch G, Schmidt G (1985) What's new in steroid and nonsteroid drug effects on gastroduodenal mucosa? Pathol Res Pract 180:437-444.

Carlson JN, Fitzgerald LW, Keller RW, Glick SD (1991) Side and region dependent changes in dopamine activation with various durations of restraint stress. Brain Res 550:313-318.

Carlson JN, Fitzgerald LW, Keller RW, Glick SD (1993) Lateralized changes in prefrontal cortical dopamine activity induced by controllable and uncontrollable stress in the rat. Brain Res 630:178-187.

Carlson JN, Visker KE, Keller Jr RW, Glick SD (1996) Left and right 6-hydroxydopamine lesions of the medial prefrontal cortex differentially alter subcortical dopamine utilization and the behavioral response to stress. Brain Res 711:1-9.

Cechetto DF, Saper CB (1990) Role of the cerebral cortex in autonomic function. In: Central regulation of autonomic functions (Loewy AD, Spyer KM, eds), pp 208-223. Oxford: Oxford UP.

Coleman-Mesches K, McGaugh JL (1995) Differential effects of pretraining inactivation of the right or left amygdala on retention of inhibitory avoidance training. Behav Neurosci 109:642-627.

Damasio AR (1994) Descartes' error. New York: Grosset/Putnam.

Damasio AR, Tranel D, Damasio H (1990) Individuals with sociopathic behavior caused by frontal damage fail to respond autonomically to social stimuli. Behav Brain Res 41:81-94.
Davidson RJ (1992) Anterior cerebral asymmetry and the nature of emotion. Brain Cogn 20:125-151.

Davidson RJ, Kalin NH, Shelton SE (1992) Lateralized effects of diazepam on frontal brain electrical asymmetries in rhesus monkeys. Biol Psychiatry 32:438-451.

Denenberg VH (1981) Hemispheric laterality in animals and the effects of early experience. Behav Brain Sci 4:1-49.

Denenberg VH, Yutzey DA (1985) Hemispheric laterality, behavioral asymmetry, and the effects of early experience in rats. In: Cerebral lateralization in nonhuman species (Glick SD, ed), pp 109-133. New York: Academic.

Deutch AY, Roth RH (1990) The determinants of stress-induced activation of the prefrontal cortical dopamine system. In: Progress in brain research, Vol 85, The prefrontal cortex: Its structure, function and pathology (Uylings HBM, Van Eden CG, De Bruin JPC, Corner MA, Feenstra MGP, eds), pp 367-403. Amsterdam: Elsevier.

Diorio D, Viau V, Meaney MJ (1993) The role of the medial prefrontal cortex (cingulate cortex) in the regulation of hypothalamic-pituitaryadrenal responses to stress. J Neurosci 13:3839-3847.

Drevets WC, Price JL, Simpson JR, Todd RD, Reich T, Vannier M, Raichle ME (1997) Subgenual prefrontal cortex abnormalities in mood disorders. Nature 386:824-827.

Feldman S, Conforti N (1985) Modifications of adrenocortical responses following frontal cortex stimulation in rats with hypothalamic deafferentations and medial forebrain bundle lesions. Neuroscience 15:1045-1047.

Freitas JE, Thrall JH, Swanson DP, Rifai A, Beierwaltes WH (1978) Normal adrenal asymmetry: explanation and interpretation. J Nucl Med 19:149-153.

Frysztak RJ, Neafsey EJ (1991) The effect of medial frontal cortex lesions on respiration, "freezing," and ultrasonic vocalizations during conditioned emotional responses in rats. Cereb Cortex 1:418-425.

Frysztak RJ, Neafsey EJ (1994) The effect of medial frontal cortex lesions on cardiovascular conditioned emotional responses in the rat. Brain Res 643:181-193.

Gainotti G (1983) Laterality of affect: the emotional behavior of right and left-brain-damaged patients. In: Hemisyndromes: psychopathology, neurology, and psychiatry (Myslobodsky MS, ed), pp 175-192. New York: Academic.

Gainotti G (1987) Disorders of emotional behaviour and of autonomic arousal resulting from unilateral brain damage. In: Duality and unity of the brain (Ottoson D, ed), pp 161-179. New York: Plenum.

George MS, Wassermann EM, Post RM (1996) Transcranial magnetic stimulation: a neuropsychiatric tool for the 21st century. J Neuropsychiatr Clin Neurosci 8:373-382.

Gerendai I, Halasz B (1997) Neuroendocrine asymmetry. Front Neuroendocrinol 18:354-381.

Glavin G, Murison R, Overmier JB, Pare WP, Bakke HK, Henke PG, Hernandez DE (1991) The neurobiology of stress ulcers. Brain Res Rev 16:301-343.

Hauger RL, Lorang M, Irwin M, Aguilera G (1990) CRF receptor regulation and sensitization of $\mathrm{ACTH}$ responses to acute ether stress during chronic intermittent immobilization stress. Brain Res 532:34-40.

Henke PG (1984) The anterior cingulate cortex and stress: Effects of chlordiazepoxide on unit- activity and stimulation-induced gastric pathology in rats. Int J Psychophysiol 2:23-32.

Henke PG, Sullivan RM, Ray A, MacDougall ME (1992) Stress ulcer modulation by chlordiazepoxide and GABA in the anterior cingulate cortex of rats. Exp Clin Gastroenterol 2:13-15.

Henriques JB, Davidson RJ (1991) Left frontal hypoactivation in depression. J Abnorm Psychol 100:535-545.

Henry JP (1997) Psychological and physiological responses to stress: The right hemisphere and the hypothalamic-pituitary-adrenal axis, an inquiry into problems of human bonding. Acta Physiol Scand [Suppl] 640:10-25.

Herman JP, Cullinan WE (1997) Neurocircuitry of stress: central control of the hypothalamo-pituitary-adrenocortical axis. Trends Neurosci 20:78-84.

Hurley, KM, Herbert H, Moga MM, Saper CB (1991) Efferent projections of the infralimbic cortex of the rat. J Comp Neurol 308:249-276.

Krey LC, Lu K, Butler W, Hotchkiss J, Piva F, Knobil E (1975) Surgical disconnections of the medial basal hypothalamus and pituitary function in the rhesus monkey. II. GH and cortisol secretion. Endocrinology 96:1088-1096. 
Lachuer J, Delton I, Buda M, Tappaz M (1994) The habituation of brainstem catecholaminergic groups to chronic daily restraint stress is stress specific like that of hypothalamo-pituitary-adrenal axis. Brain Res 638:196-202.

LaHoste GJ, Mormede P, Rivet J-M, LeMoal M (1988) Differential sensitization to amphetamine and stress responsivity as a function of inherent laterality. Brain Res 453:381-384.

McEwen BS, De Kloet ER, Rostene WH (1986) Adrenal steroid receptors and actions in the nervous system. Physiol Rev 66:1121-1150.

Meadows M-E, Kaplan RF (1994) Dissociation of autonomic and subjective responses to emotional slides in right hemisphere damaged patients. Neuropsychologia 32:847-856.

Meaney MJ, Aitken DH (1985) $\left[{ }^{3} \mathrm{H}\right]$ Dexamethasone binding in rat frontal cortex. Brain Res 328:176-180.

Neafsey EJ (1990) Prefrontal cortical control of the autonomic nervous system: anatomical and physiological observations. In: Progress in brain research, Vol 85, The prefrontal cortex: Its structure, function and pathology (Uylings HBM, Van Eden CG, De Bruin JPC, Corner MA, Feenstra MGP, eds), pp 147-166. Amsterdam: Elsevier.

Otto MW, Fava M, Rosenbaum JF, Murphy CF (1991) Perceptual asymmetry, plasma cortisol, and response to treatment in depressed outpatients. Biol Psychiatry 30:703-710.

Paxinos G, Watson C (1982) The rat brain in stereotaxic coordinates. New York: Academic.

Ray A, Henke PG, Sullivan RM (1988) Central dopamine systems and gastric stress pathology in rats. Physiol Behav 42:359-364.

Ray A, Sullivan RM, Henke PG (1987) Adrenergic modulation of gastric stress pathology in rats: a cholinergic link. J Autonom Nerv Sys 20:265-268.

Rubin RT, Phillips JJ (1991) Adrenal gland volume determination by computed tomography and magnetic resonance imaging in normal subjects. Invest Radiol 26:465-469.

Scatton B, D'Angio M, Driscoll P, Serrano AK (1988) An in vivo voltammetric study of the response of mesocortical and mesoaccumbens dopaminergic neurons to environmental stimuli in strains of rats with differing levels of emotionality. Ann NY Acad Sci 537:124-137.

Schaffer CE, Davidson RJ, Saron C (1983) Frontal and parietal electroencephalogram asymmetry in depressed and nondepressed subjects. Biol Psychiatry 18:753-762.

Schore AN (1996) The experience-dependent maturation of a regulatory system in the orbital prefrontal cortex and the origin of developmental psychopathology. Dev Psychopathol 8:59-87.
Schore AN (1997) Early organization of the nonlinear right brain and development of a predisposition to psychiatric disorders. Dev Psychopathol 9:595-631.

Scribner KA, Walker C-D, Cascio CS, Dallman MF (1991) Chronic streptozotocin diabetes in rats facilitates the acute stress response without altering pituitary or adrenal responsiveness to secretagogues. Endocrinology 129:99-108.

Slopsema JS, VanDerGugten J, DeBruin JPC (1982) Regional concentrations of noradrenaline and dopamine in the frontal cortex of the rat: dopaminergic innervation of the prefrontal subareas and lateralization of prefrontal dopamine. Brain Res 250:197-200.

Spencer RL, McEwen BS (1990) Adaptation of the hypothalamicpituitary-adrenal axis to chronic ethanol stress. Neuroendocrinology 52:481-89.

Sullivan RM, Gratton A (1998) Relationships between stress-induced increases in medial prefrontal cortical dopamine and plasma corticosterone levels in rats: role of cerebral laterality. Neuroscience 83:81-91.

Sullivan RM, Henke PG (1986) The anterior midline cortex and adaptation to stress ulcers in rats. Brain Res Bull 17:493-496.

Sullivan RM, Szechtman H (1994) Left/right nigrostriatal asymmetry in susceptibility to neurotoxic dopamine depletion with 6-hydroxydopamine in rats. Neurosci Lett 170:83-86.

Sullivan RM, Szechtman H (1995) Asymmetrical influence of mesocortical dopamine depletion on stress ulcer development and subcortical dopamine systems in rats: implications for psychopathology. Neuroscience 65:757-766.

Sullivan RM, Talangbayan H, Einat H, Szechtman H (1998) Effects of quinpirole on central dopamine systems in sensitized and nonsensitized rats. Neuroscience 83:781-790.

Szigethy E, Conwell Y, Forbes NT, Cox C, Caine ED (1994) Adrenal weight and morphology in victims of completed suicide. Biol Psychiatry 36:374-380.

Terreberry RR, Neafsey EF (1987) The rat medial frontal cortex projects directly to autonomic regions of the brainstem. Brain Res Bull 19:639-649.

Thierry AM, Tassin JP, Blanc G, Glowinski J (1976) Selective activation of mesocortical DA systems by stress. Nature 263:242-243.

Wittling W (1997) The right hemisphere and the human stress response. Acta Physiol Scand [Suppl[rsb] 640:55-59.

Wittling W, Schweiger E (1993) Alterations of neuroendocrine brain asymmetry: a neural risk factor affecting physical health. Neuropsychobiology 28:25-29. 